\title{
Wada serca typu criss-cross heart współwystępująca z malpozycją wielkich naczyń i dekstrokardią - kompleksowe leczenie złożonej wrodzonej wady układu sercowo-naczyniowego o rzadkiej morfologii
}

\section{Criss-cross heart, dextrocardia and transposition of the great arteries - comprehensive management of a complex cardiovascular defect and rare morphology}

\author{
Julia Haponiuk ${ }^{1}$, Maciej Chojnicki ${ }^{1}$ (D), Katarzyna Leszczyńska ${ }^{2}$ (D) Konrad Paczkowski ${ }^{1}$ (D) \\ Mariusz Steffens ${ }^{1}$, Anna Romanowicz-Sołtyszewska ${ }^{1}$ (D), Marta Paśko-Majewska ${ }^{1}$ (D), \\ Monika Opacian-Bojanowska ${ }^{1}$ (D), Katarzyna Gierat-Haponiuk ${ }^{3}$ (D), \\ Paweł Macko ${ }^{1}$, Ireneusz Haponiuk ${ }^{1,3}$ iD
}

${ }^{1}$ Oddział Kardiochirurgii Dziecięcej Szpital św. Wojciecha w Gdańsku-Zaspie, Copernicus PL

${ }^{2}$ Katedra i Klinika Ginekologii i Położnictwa Gdańskiego Uniwersytetu Medycznego, Uniwersyteckie Centrum Kliniczne w Gdańsku ${ }^{3}$ Katedra Zdrowia i Nauk Biologicznych Akademii Wychowania Fizycznego i Sportu im. Jędrzeja Śniadeckiego w Gdańsku

\section{Streszczenie}

Wrodzona wada serca (CHD) typu criss-cross heart (CCH) współwystępująca ze skrzyżowaniem napływów przedsionkowo-komorowych jest bardzo rzadką, złożoną odmianą anatomiczną polegającą na nieprawidłowej rotacji komór wokół długiej osi serca. Częstość występowania tej anomalii stanowi mniej niż 0,1\% wszystkich CHD. U pacjentów z CCH stwierdza się również ubytki w przegrodzie międzykomorowej (VSD), malpozycję wielkich naczyń, podwójny odpływ i/lub hipoplazję prawej komory (RV), stenozę tętnicy płucnej (PA) i hipoplazję zastawki trójdzielnej.

Zaprezentowano przypadek 7-miesięcznego niemowlęcia płci żeńskiej w trakcie etapowego leczenia kardiochirurgicznego, po przezskórnej balonoplastyce zastawki płucnej oraz po operacyjnym, prawostronnym, zmodyfikowanym zespoleniu systemowo-płucnym metodą Blalock-Tsussig (BT dex) w okresie noworodkowym.

Wadę serca rozpoznano prenatalnie oraz potwierdzono po urodzeniu. W badaniu echokardiograficznym uwidoczniono $\mathrm{CHD}$ typu $\mathrm{CCH}$ - skrzyżowanie napływów oraz nieprawidłowe połączenia przedsionkowo-komorowe (RV połączona przez zastawkę trójdzielną z lewym przedsionkiem i lewa komora połączona przez zastawkę mitralną z prawym przedsionkiem). Ponadto stwierdzono zwężenie zastawkowe i podzastawkowe PA (gradient RV/PA ok. $90 \mathrm{~mm} \mathrm{Hg}$ ), rozległy VSD, malpozycję wielkich naczyń (aorta odchodząca z RV i PA znad VSD) oraz drożne zespolenie BT dex. Niemowlę nie wykazywało cech duszności mimo lekkiej sinicy, a jego rozwój psychoruchowy był adekwatny do wieku. Po diagnostycznym cewnikowaniu serca w krążeniu pozaustrojowym wykonano operację dwukierunkowego zespolenia Glenna (zespolenie żyły głównej górnej z prawą PA), z usunięciem zespolenia BT dex i zamknięciem pnia PA. Zabieg przebiegł bez powikłań. Ponad 90\% przypadków CHD typu criss-cross występuje w lewostronnym położeniu serca, a współwystępowanie malpozycjli wielkich naczyń i dekstrokardii, według najlepszej wiedzy autorów, to drugi taki opisany przypadek. Mimo rzadkości występowania odmiany anatomiczne zawsze powinny być brane pod uwagę, zwłaszcza podczas prenatalnej diagnostyki klinicznej, i precyzyjnie zdefiniowane w okresie kwalifikacji do leczenia operacyjnego.

Słowa kluczowe: criss-cross heart, dekstrokardia, malpozycja wielkich naczyń, wrodzone wady serca, kardiochirurgia dziecięca

Folia Cardiologica 2020; 15, 1: 72-75

Adres do korespondencji: dr hab. n. med. Ireneusz Haponiuk, Oddział Kardiochirurgii Dziecięcej, Szpital św. Wojciecha w Gdańsku-Zaspie, Copernicus PL, Al. Jana Pawła II 50, 80-462 Gdańsk-Zaspa, tel. +48 587684 881, faks +48 587684 882, e-mail: ireneusz_haponiuk@poczta.onet.pl 


\section{Wstęp}

Powszechny rozwój diagnostyki prenatalnej spowodował zwiększenie liczby żywych urodzeń noworodków z wrodzoną wadą serca (CHD, congenital heart defect), osiągając liczbę 9410 na 1000 urodzeń w latach 2010-2017 [1]. Wrodzona wada serca typu criss-cross heart (CCH) współwystępująca ze skrzyżowaniem napływów przedsionkowo-komorowych (AV, atrioventricular) jest bardzo rzadką, złożoną odmianą anatomiczną, w której, podczas rozwoju płodu wskutek nieprawidłowej rotacji komór wokół długiej osi serca, przemieszczeniu ulega koniuszek serca, a podstawa serca i zastawki AV pozostają na miejscu. [2, 3]. Według aktualnych danych częstość występowania tej wady to mniej niż 0,1\% wszystkich CHD oraz nie więcej niż 8 przypadków na milion żywych urodzeń $[4,5]$. Criss-cross heart można zaobserwować w trzech postaciach: pełnej transpozycji (z ang. dextro-transposition of great arteries), skorygowanej transpozycji (z ang levo-ttransposition of great arteries) oraz w funkcjonalnie prawidłowych sercach. Fizjologia oraz występujące objawy zależą od obecności i stopnia skrzyżowania drogi napływu, morfologii połączenia AV, jak również od współwystępujących wad serca [5].

U pacjentów z CCH najczęściej stwierdza się współwystępujące ubytki w przegrodzie międzykomorowej (VSD, ventricular septal defect), malpozycję wielkich naczyń, podwójny odpływ i/lub hipoplazję prawej komory (RV, right ventricle), stenozę tętnicy płucnej (PA, pulmonary artery) i hipoplazję zastawki trójdzielnej [4]. Postępowanie terapeutyczne w przypadku CCH zależy od możliwości zachowania funkcji obu komór serca, natomiast zazwyczaj stosuje się kardiochirurgiczne leczenie szlakiem fizjologicznej paliacji w celu osiągnięcia funkcjonalnej pojedynczej komory systemowej [6].

\section{Opis przypadku}

W niniejszej pracy zaprezentowano przypadek 7-miesięcznego niemowlęcia płci żeńskiej z CHD pod postacią $\mathrm{CCH}$ w trakcie etapowego leczenia metodą fizjologicznej paliacji - szlakiem pojedynczej komory. Pacjentka z CHD rozpoznaną prenatalnie urodziła się siłami natury w 38 . tygodniu ciąży, uzyskała 10 punktów w skali Apgar, a proces adaptacji przebiegł bez powikłań. Po urodzeniu wykonano przezskórną balonoplastykę zastawki płucnej oraz prawostronne, zmodyfikowane zespolenie systemowo-płucne metodą Blalock-Taussig (BT dex) w okresie noworodkowym.

W dalszej obserwacji w badaniu echokardiograficznym potwierdzono CHD typu CCH - skrzyżowanie napływów oraz nieprawidłowe połączenia AV (RV połączona przez zastawkę trójdzielną z lewym przedsionkiem i lewa komora połączona przez zastawkę mitralną z prawym przedsionkiem). Ponadto stwierdzono zwężenie zastawkowe i podzastawkowe PA (gradient RV/PA ok. 90 mm Hg), rozległy VSD, malpozycję wielkich naczyń (aorta odchodząca z RV i PA znad VSD) oraz drożne zespolenie BT dex (ryc. 1A i 1B). Niemowlę nie wykazywało cech duszności mimo lekkiej sinicy, a rozwój psychoruchowy dziecka był adekwatny do wieku. Po diagnostycznym cewnikowaniu serca pacjentkę zakwalifikowano do dalszego leczenia kardiochirurgicznego (ryc. 1C). W krążeniu pozaustrojowym wykonano operację dwukierunkowego zespolenia Glenna (zespolenie żyły głównej górnej z prawą PA). Podczas zabiegu usunięto zespolenie BT dex i zamknięto pień PA. Zabieg oraz okres pooperacyjny przebiegły bez powikłań (ryc. 1D).

\section{Dyskusja}

Ponad 90\% przypadków wady wrodzonej typu CCH występuje w lewostronnym położeniu serca, a współwystępowanie malpozycjli wielkich naczyń i dekstrokardii, według najlepszej wiedzy autorów, to po publikacji Kasar i wsp. drugi taki opisany przypadek.

Wybór postępowania w przypadku CCH zależy od wnikliwej oceny indywidualnej morfologii wady oraz jej hemodynamiki, a ostateczną decyzję determinuje możliwość zachowania funkcji obu komór serca. Rozważa się możliwość docelowego wykonania takich procedur, jak procedura Rastelli, operacja Jatene'a, zespolenie Glenna czy wytworzenie centralnego zespolenia systemowo-płucnego (ang. central shunt). Analiza kilku przypadków dorosłych pacjentów z wadą serca o morfologii $\mathrm{CCH}$ wskazuje jednak, że follow-up zależy głównie od manifestacji klinicznej, diagnozowanej jako pierwotne zaburzenia hemodynamiki, oraz od kompleksowego zaopatrzenia kardiochirurgicznego. Zdecydowanie mniejsze znaczenie ma zasadnicza anatomia wady podstawowej [7].

Badanie echokardiograficzne pozwala wysunąć podejrzenie CHD pod postacią CCH, szczególnie jeśli nie można uwidocznić równoległego ustawienia zastawek AV ani napływów komór oraz gdy obu tych zastawek nie można spontanicznie zwizualizować jednocześnie w 4-jamowej projekcji koniuszkowej [5]. Co więcej, w diagnostyce $\mathrm{CCH}$ opisuje się również wykorzystanie rezonansu magnetycznego (MRI, magnetic resonance imaging) w celu dokładnej oceny morfologii wady przed zabiegiem [8].

\section{Wnioski}

Mimo rzadkości występowania odmiany anatomiczne zawsze powinny być brane pod uwage, zwłaszcza podczas prenatalnej diagnostyki klinicznej, i precyzyjnie zdefiniowane w okresie kwalifikacji do leczenia operacyjnego.

\section{Konflikt interesów}

Autorzy deklarują brak konfliktu interesów. 

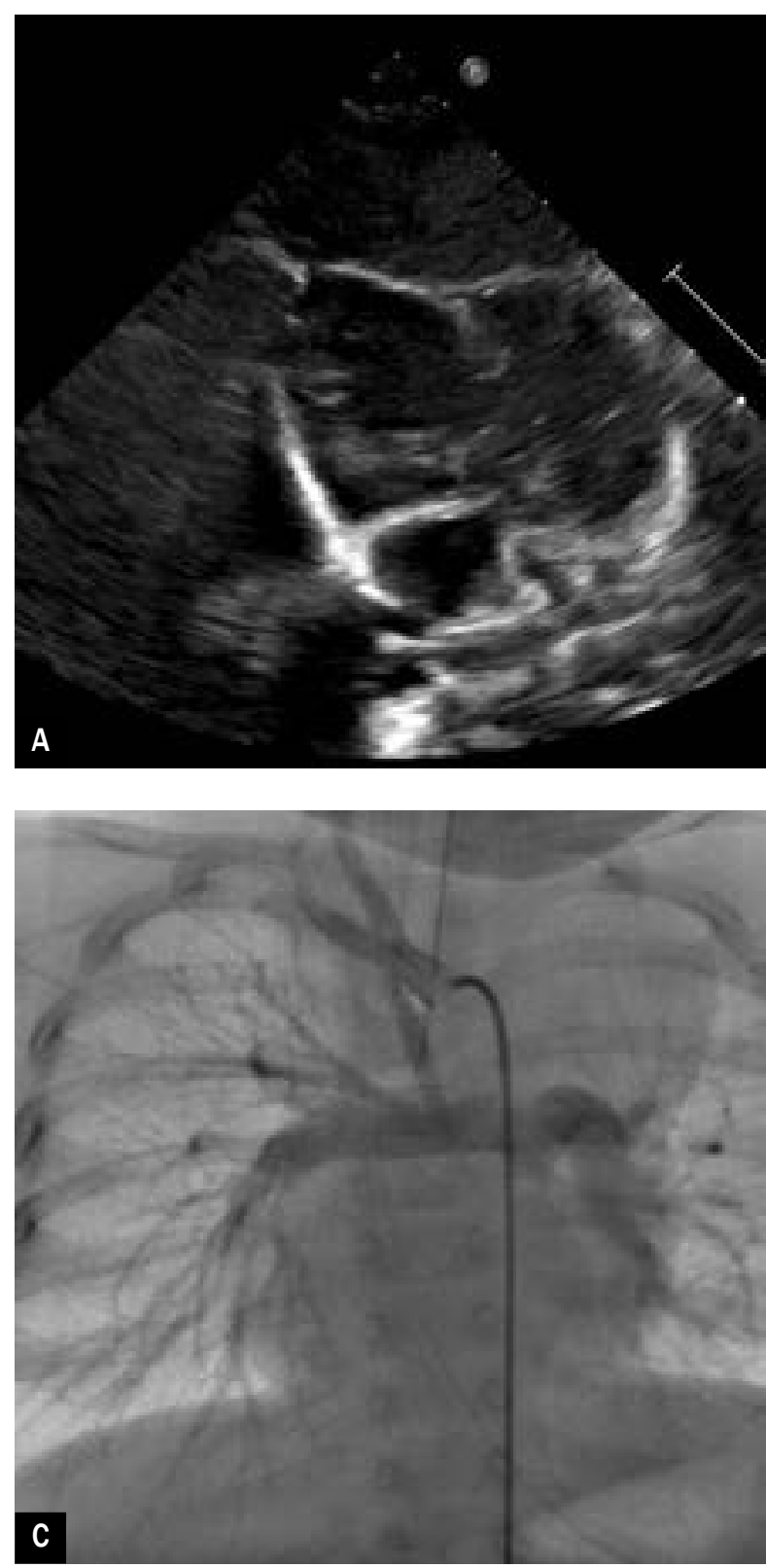
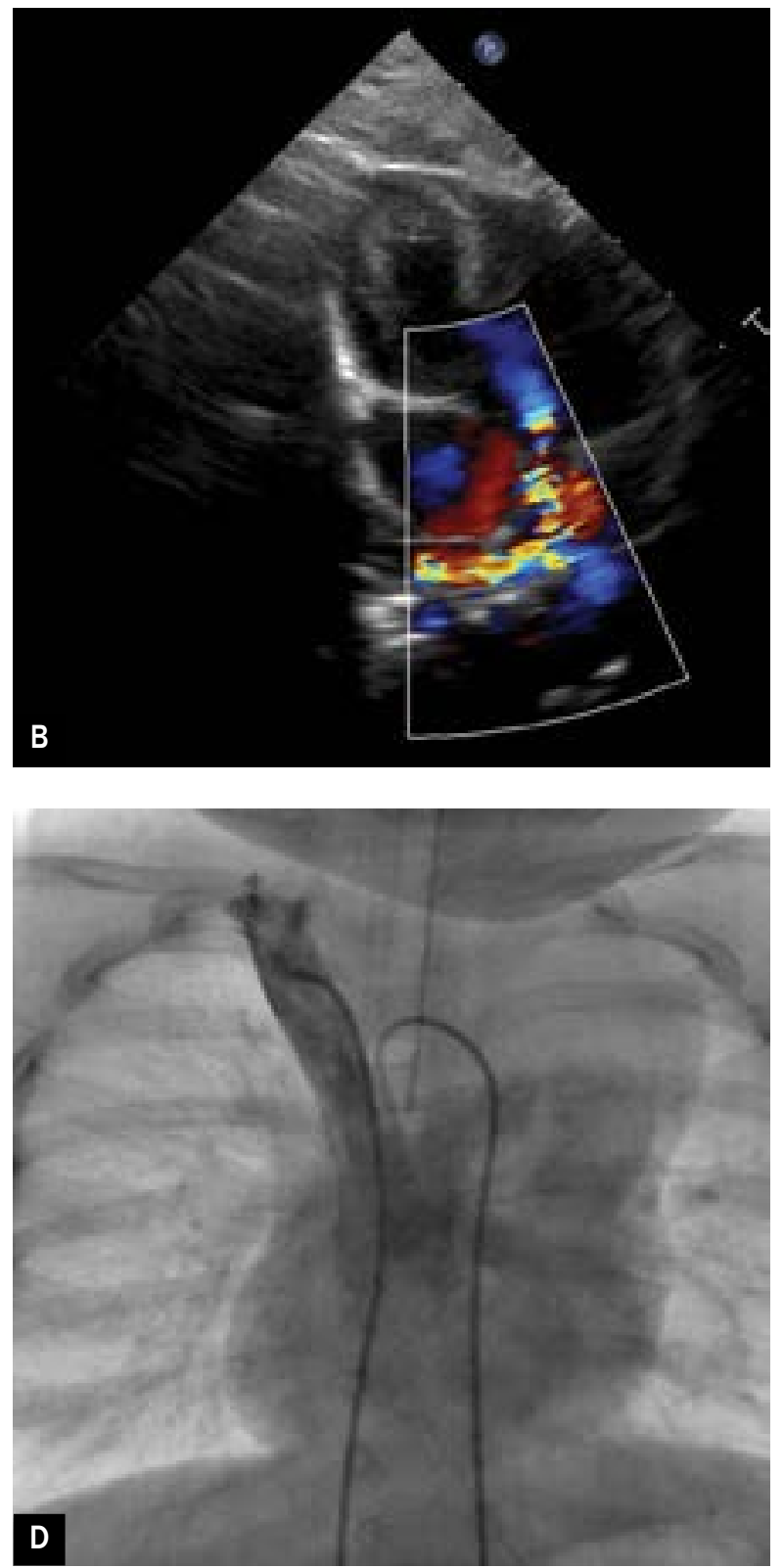

Rycina 1A. Badanie echokardiograficzne, projekcja podżebrowa (oś krótka): przedsionek o morfologii prawego przedsionka połączony zastawką trójdzielną z lewą komorą oraz przedsionek o morfologii lewego przedsionka połączony zastawką mitralną z prawą komorą; B. Badanie echokardiograficzne, projekcja koniszkowa 5-jamowa: stenoza tętnicy płucnej (PA, pulmonary artery). C. Diagnostyczne cewnikowanie serca: napływ z prawej tętnicy podobojczykowej przez drożne zespolenie systemowo-płucne metodą Blalock-Tsussig do PA; D. Poperacyjne cewnikowanie serca: napływ z żyły głównej górnej do tętnic płucnych, dekstrokardia - koniuszek serca skierowany w prawą stronę

\section{Abstract}

The criss-cross heart congenital defect (CHD) concomitant with transposition of the great arteries has an incidence of less than $0.1 \%$ of all inherited heart anatomy abnormalities. It derives from the anomaly of cardiac rotation around its long axis after ventricular septation, and results in an atypical relation between the ventricles and the atria. Furthermore, such patients may also present with ventricular septal defect (VSD), large vessel malposition, double outflow and/or right ventricular hypoplasia (RV), pulmonary artery stenosis (PA), and tricuspid valve hypoplasia. 
Its management is determined by the potential to preserve the function of both ventricles, although usually single-ventricle repair is applied.

A 7-month-old patient after a transcatheter pulmonary balloon valvuloplasty and a surgical unilateral modified Blalock-Taussig (BT) shunt was admitted to the paediatric cardiac surgery department for further treatment.

CHD had been diagnosed prenatally and confirmed after birth. Echocardiographic study revealed dextrocardia and a criss-cross heart pathology with discordant atrioventricular (AV) and ventriculoarterial relations. Intracardiac pathology was concomitant with transposition of the great arteries [aorta originating from the RV, and PA from above the VSD], subvalvular and valvular pulmonary stenosis (gradient RV/PA approx. $90 \mathrm{mmHg}$ ), and unobstructed BT shunt. Systemic cyanosis was not observed, and the child's mental and physical development was undisturbed. After diagnostic catheterisation, the patient was referred for further surgery.

Using extracorporeal circulation, a bidirectional Glenn anastomosis was performed, and the BT shunt as well as the PA were closed and dissected. The postoperative course was uncomplicated.

More than $90 \%$ of criss-cross hearts co-occur with levocardia. Concomitance with AV-related transposition of the great arteries and dextrocardia, to the best of our knowledge, is here described in the literature for only the second time. Thus, the diagnosis of a rare congenital heart defect should be always considered, especially in prenatal diagnostics, and precisely defined during qualification for further surgical treatment.

Key words: criss-cross heart, dextrocardia, transposition on the great arteries, congenital heart defects, peadiatric cardiac surgery

Folia Cardiologica 2020; 15, 1: 72-75

\section{Piśmiennictwo}

1. Liu Y, Chen S, Zühlke L, et al. Global birth prevalence of congenital heart defects 1970-2017: updated systematic review and meta-analysis of 260 studies. Int J Epidemiol. 2019; 48(2): 455-463, doi: 10.1093/ /ije/dyz009, indexed in Pubmed: 30783674.

2. Anderson RH, Shinebourne EA, Gerlis LM. Criss-cross atrioventricular relationships producing paradoxical atrioventricular concordance or discordance. Their significance to nomenclature of congenital heart disease. Circulation. 1974; 50(1): 176-180, doi: 10.1161/01. cir.50.1.176, indexed in Pubmed: 4835263.

3. Manuel D, Ghosh G, Joseph G, et al. Criss-cross heart: transthoracic echocardiographic features. Indian Heart J. 2018; 70(1): 71-74, doi: 10.1016/j.ihj.2017.03.008, indexed in Pubmed: 29455791.

4. Kasar T, Ayyıldız P, Türkvatan A, et al. Criss-cross heart with dextrocardia and transposition of the great arteries: a rare pathology. Turk Kardiyol Dern Ars. 2016; 44(1): 91, doi: 10.5543/tkda.2015.00057, indexed in Pubmed: 26875142.
5. Taksande AM. Echocardiographic recognition of a criss-cross heart with double outlet right ventricle. Images Paediatr Cardiol. 2013; 15(2): 3-7, indexed in Pubmed: 23847656.

6. Danielson GK, Tabry IF, Ritter DG, et al. Surgical repair of criss-cross heart with straddling atrioventricular valve. J Thorac Cardiovasc Surg. 1979; 77(6): 847-851, indexed in Pubmed: 374883.

7. Hoffman P, Szymański P, Lubiszewska B, et al. Crisscross hearts in adults: echocardiographic evaluation and natural history. J Am Soc Echocardiogr. 2009; 22(2): 134-140, doi: 10.1016/j.echo.2008.10.004, indexed in Pubmed: 19056236.

8. Cantinotti M, Bell A, Hegde S, et al. A segmental approach to criss-cross heart by cardiac MRI. Int J Cardiol. 2007; 118(3): e103-e105, doi: 10.1016/j.ijcard.2007.01.063, indexed in Pubmed: 17400312. 